\section{Influence of changes in cholesterol levels and disease activity on the 10 years cardiovascular risk estimated with different algorithms in rheumatoid arthritis patients}

European League Against Rheumatism (EULAR) recommendations for cardiovascular (CV) risk management in patients with Rheumatoid Arthritis (RA) suggest to 'measure cholesterol and other lipid fractions when disease activity is stable or in remission'. This point ensues from the assumption that inflammation and high disease activity can lower lipid levels and mislead the CV risk score, despite the risk of CV disease is reported to be increased in patients with active RA. ${ }^{2}$ As algorithms used in clinical practice include total cholesterol (Tot-Chol) and its fractions as variable of interest, we would like to raise the question whether lipid levels and disease activity changes during the first months of biological treatment may have an impact on the ordinary CV risk scores. We analysed RA patients included in the BIOlogic aPUlian REgistry (BIOPURE) (Ethics Review Board of Policlinico of Bari, comitatoetico@policlinico.ba.it, protocol number 5277), who started a first-line biological agent since January 2010 having all data to calculate the 10 years CV risk score either at baseline (ie, with active disease), at 3-month and at 6-month follow-up, when disease activity was assumed stable. Exclusion criteria were the coexisting or prior CV disease (including ischaemic heart disease, cerebrovascular accident), the biological drug discontinuation for any cause, the lipid-lowering treatment during the study-time. Hyperlipidaemia was considered as a Tot-Chol $\geq 240 \mathrm{mg} / \mathrm{dL}$ or hypertriglyceridaemia $>200$ $\mathrm{mg} / \mathrm{dL}$, whereas hypertension was defined as a systolic blood pressure $\geq 140 \mathrm{~mm} \mathrm{Hg}$ and/or a diastolic blood pressure $\geq 90$ $\mathrm{mm} \mathrm{Hg}$, and/or a diagnosis of hypertension by a physician. CV risk was estimated using either the QRISK3-2018 calculator, ${ }^{3}$ the Reynold Risk score (RRS), ${ }^{4}$ the 'Progetto Cuore' Italian score, an adapted algorithm that replicates the Systematic Coronary Risk Evaluation project charts of European Society of Cardiology, ${ }^{5}$ and the Expanded Risk Score in RA (ERS-RA), the latter including disease related domains as dichotomous variables to facilitate its use in rheumatologists' daily practice. ${ }^{6}$ The results of the algorithms not including RA among the variables ('Progetto Cuore' and RRS) were multiplied by 1.5 , in accordance to the EULAR recommendations. ${ }^{1}$ RRS was the only including $\mathrm{C}$ reactive protein among its factors (online supplementary table 1). Demographics and clinical data were evaluated using standard descriptive statistics. The Wilcoxon signed-rank test was used to compare CV risk changes throughout the time frame of the study. The SPSS IBM Software (V.21.0) was used for statistical analysis.

The cohort included 112 RA patients (86 females; mean age $52.8 \pm 12.9$ years, mean disease duration 58.6 \pm 76.4 months) who started a biological agent due to active disease (55 antitumour necrosis factor alpha agents, 33 abatacept and 24 tocilizumab). Clinical characteristics and serum lipid changes are shown in table 1 . Tot-Chol levels significantly increased after 3 months $(p=0.006)$ and returned to baseline level at 6 months $(\mathrm{p}=0.22)$. But, high density lipoprotein (HDL), Tot-Chol/ HDL ratio and triglycerides did not show significant change throughout 6 months. Concerning CV risk scores, ERS-RA decreased already after 3 months, and a trend towards decrease

\begin{tabular}{|c|c|c|c|}
\hline Variables & Baseline & 3 months & 6 months \\
\hline CDAI & $18.3(12.7)$ & $8(7.8)^{* * *}$ & $5.9(4.2)^{* * *}$ \\
\hline mHAQ-DI & $0.9(0.8)$ & $0.7(0.8)^{\star * *}$ & $0.6(0.7)^{\star * *}$ \\
\hline Glucocorticoids dose, mg/dL & $4.3(3.4)$ & $3.5(2.5)^{* *}$ & $2.9(2.4)^{* * *}$ \\
\hline Glucocorticoids, n (\%) & $79(70.5)$ & $72(64.3)$ & $67(59.8)^{* *}$ \\
\hline csDMARDs, n (\%) & $97(86.5)$ & $94(83.9)$ & $91(81.3)$ \\
\hline Systolic blood pressure, $\mathrm{mm} \mathrm{Hg}$ & $126.7(16.8)$ & $124.3(17.3)$ & $124.9(18.2)$ \\
\hline Diastolic blood pressure, mm Hg & $78.8(9.4)$ & $77.6(9.6)$ & $78.2(10.7)$ \\
\hline Total cholesterol, mg/dL & $197.3(38.2)$ & $205.8(37.3)^{* *}$ & $201(34.6)$ \\
\hline HDL-cholesterol, mg/dL & $60.1(16.9)$ & $62.9(15.9)$ & $61.8(15.5)$ \\
\hline Tot-Chol/HDL ratio & $3.4(1.1)$ & $3.4(0.9)$ & $3.4(0.9)$ \\
\hline Triglycerides, mg/dL & $112.3(78.2)$ & $111.1(61.5)$ & $109.1(53.7)$ \\
\hline $\mathrm{CRP}, \mathrm{mg} / \mathrm{L}$ & $12.8(17.1)$ & $6.6(10.5)^{* * *}$ & $6.2(8.5)^{* * *}$ \\
\hline $\mathrm{BMI}, \mathrm{kg} / \mathrm{m}^{2}$ & $25.6(5.4)$ & $26(4.9)$ & $25.6(4.9)$ \\
\hline Diabetes, n (\%) & $6(5.4)$ & $7(6.3)$ & $7(6.3)$ \\
\hline Hyperlipidaemia, n (\%) & $45(40.2)$ & $70(62.5)^{* * *}$ & $66(58.9)^{* *}$ \\
\hline Hypertension, n (\%) & $31(27.7)$ & $32(28.6)$ & $32(28.6)$ \\
\hline Hypertension therapy, $\mathrm{n}(\%)$ & $26(23.2)$ & $29(25.9)$ & $30(26.8)$ \\
\hline 'Progetto Cuore' nr.112 & $6.9(11.3)$ & $6.7(11.1)$ & $7(11.9)$ \\
\hline $\begin{array}{l}\text { QRISK3-2018 } \\
\text { nr.112 }\end{array}$ & $10.8(11.3)$ & $10.3(10.8)$ & $10.4(11.4)$ \\
\hline RRS nr.105 & $6.9(8.8)$ & $6(6.9)$ & $5.8(6.9)^{* *}$ \\
\hline ERS-RA nr.112 & $10.8(11.9)$ & $9.8(10.9)^{* *}$ & $9.6(10.5)^{* * *}$ \\
\hline
\end{tabular}

Values are expressed as mean (SD) unless otherwise indicated. Seven patients with diabetes were excluded in the calculation of RRS as diabetes was an exclusion criteria. ${ }^{*} \mathrm{P}<0.05 ;{ }^{*} \mathrm{p}<0.01 ;{ }^{* *} \mathrm{p}<0.001$ versus baseline.

BMI, body mass index; CDAI, Clinical Disease Activity Index; CRP, C reactive protein; csDMARDs, conventional synthetic disease modifying antirheumatic drugs; ERS-RA, Expanded Risk Score in Rheumatoid Arthritis; HDL, high density lipoprotein; RRS, Reynolds Risk score; Tot-Chol, total cholesterol; mHAQ-DI, modified Health Assessment Questionnaire Disability Index. 
persisted at 6 months. RRS showed a decrease of estimated CV risk score only after 6 months. On the contrary the 'Progetto Cuore' and the QRISK3-2018 scores did not change neither at three nor at 6 months of follow-up (table 1).

Our study shows that the changes in lipid levels and disease activity have different weight on different CV risk scores. Changes in disease activity influence algorithms encompassing RA-related CV risk factors, such as RRS and ERS-RA, for which the timing can impact on the score result. Instead, since QRISK32018 and 'Progetto Cuore' scores seem not suffer of the changes in Tot-Chol levels and disease activity, they may be used at any time and level of disease activity by rheumatologists in daily clinical practice.

\section{Marco Fornaro $\bullet$, Fabio Cacciapaglia, Vincenzo Venerito, Giuseppe Lopalco $\odot$, Florenzo lannone $\bullet$}

Department of Emergency and Organ Transplantation, Rheumatology Unit, University of Bari, Bari, Italy

Correspondence to Florenzo lannone, Department of Emergency and Organ Transplantation, Rheumatology Unit, University of Bari, Piazza Giulio Cesare, 11, 70124 Bari, Italy; florenzo.iannone@uniba.it

Contributors MF and FC contributed equally to this work. MF and FC designed the study; MF, GL and VV collected clinical data; MF and VV performed statistical analysis; FC, MF and FI wrote the final draft; MF and GL performed the bibliographic research; MF and FI are responsible for the intellectual integrity of the study.

Funding This research received no specific grant from any funding agency in the public, commercial or not-for-profit sectors.

Competing interests No, there are no competing interests for any author.

Patient consent for publication Not required.

Provenance and peer review Not commissioned; internally peer reviewed.

(c) Author(s) (or their employer(s)) 2020. No commercial re-use. See rights and permissions. Published by BMJ.

- Additional material is published online only. To view please visit the journal online (http://dx.doi.org/10.1136annrheumdis-2019-215715).
MF and FC contributed equally.

\section{A) Check for updates}

To cite Fornaro M, Cacciapaglia F, Venerito V, et al. Ann Rheum Dis 2020;79:e104.

Received 13 May 2019

Accepted 17 May 2019

Published Online First 29 May 2019

\section{S Linked}

http://dx.doi.org/10.1136/annrheumdis-2019-215748

Ann Rheum Dis 2020;79:e104. doi:10.1136/annrheumdis-2019-215715

\section{ORCID iDs}

Marco Fornaro http://orcid.org/0000-0003-1716-7432

Giuseppe Lopalco http://orcid.org/0000-0003-4524-9566

Florenzo lannone http://orcid.org/0000-0003-0474-5344

\section{REFERENCES}

1 Agca R, Heslinga SC, Rollefstad S, et al. EULAR recommendations for cardiovascular disease risk management in patients with rheumatoid arthritis and other forms of inflammatory joint disorders: 2015/2016 update. Ann Rheum Dis 2017;76:17-28.

2 Robertson J, Peters MJ, McInnes IB, et al. Changes in lipid levels with inflammation and therapy in RA: a maturing paradigm. Nat Rev Rheumatol 2013;9:513-23.

3 Hippisley-Cox J, Coupland C, Brindle P. Development and validation of QRISK3 risk prediction algorithms to estimate future risk of cardiovascular disease: prospective cohort study. BMJ 2017;357.

4 Ridker PM, Buring JE, Rifai N, et al. Development and validation of improved algorithms for the assessment of global cardiovascular risk in women: the Reynolds risk score. JAMA 2007:297:611-9.

5 Donfrancesco C, Palmieri L, Cooney M-T, et al. Italian cardiovascular mortality charts of the CUORE project: are they comparable with the score charts? Eur J Cardiovasc Prev Rehabil 2010:17:403-9.

6 Solomon DH, Greenberg J, Curtis JR, et al. Derivation and internal validation of an expanded cardiovascular risk prediction score for rheumatoid arthritis: a consortium of rheumatology researchers of North America registry study. Arthritis Rheumatol 2015;67:1995-2003. 